\title{
Self-Esteem in Children and Adolescents with Growth Hormone
} Deficiency

\author{
Héla Ayadi ${ }^{1}$, Leila Cherif ${ }^{1}$, Imen Hadjkacem ${ }^{1}$, Wiem Kammoun ${ }^{1,{ }^{*}}$, Khaoula Khemakhem ${ }^{1}$, Souhel \\ Khemekhem $^{1}$, Yousr Moalla ${ }^{1}$, Thouraya Kammoun ${ }^{2}$, Mongia Hachicha ${ }^{2}$ and Farhat Ghribi ${ }^{1}$ \\ ${ }^{1}$ Child Psychiatry Department, Hedi Chaker University Hospital, Sfax, Tunisia \\ ${ }^{2}$ Pediatric Department, Hedi Chaker University Hospital, Sfax, Tunisia \\ "Corresponding author: Child Psychiatry Department, Hedi Chaker University Hospital, Road El Ain 0.5 Km, Sfax, Tunisia. Tel: +216-58373722, Fax: +216-74298200, Email: \\ wiem.kamoun@gmail.com
}

Received 2015 November 05; Revised 2016 September 17; Accepted 2016 September 20.

\begin{abstract}
Background: The aim of this study was to assess self-esteem in children and adolescents with growth hormone deficiency and to establish the factors influencing self-esteem in children and adolescents with growth hormone deficiency.

Methods: This cross-sectional study was carried out on 26 children and adolescents, aged 8 to 18 , with a total growth hormone deficiency. The Cooper Smith self-esteem inventory was used in this study.

Results: Patients with growth hormone deficiency had low self-esteem in more than $50 \%$ of the cases. Among the studied factors influencing the self-esteem, such as school performance, disturbance in parent-child and peers-child relationships, perceived by parents, and parents' acceptance of the illness, there was a correlation in most of the subscales.

Conclusions: Growth hormone impaired children and adolescents require psychological counseling and comprehensive care.
\end{abstract}

Keywords: Growth Hormone Deficiency, Self-Esteem, Children, Adolescents

\section{Background}

The literature predominantly supports the view that chronic diseases assume the management of a new selfrepresentation, and that healing is an active construct and a learning process to live with limits. It represents a disruption of self-representation and feelings of invincibility, as well as defensive management reconsideration $(1,2)$. In fact, disease is the first threat to this narcissism that creates difficulty in the sick or mutilated body investment. In general, disease may affect the physical and psychological integrity. It also leads to a weak position and a dependency on doctors, on cares with loss of autonomy, on relatives, and on all the life factors $(3,4)$. In this context, growth hormone deficiency (GHD) constitutes the clearest demonstration of chronic disease psychological repercussions. As a matter of fact, GHD will inevitably lead to a growth delay in a critical period of the development. Furthermore, treatment with synthetic growth hormone (GH) is often slow and requires regular daily injections. All these may negatively affect child and adolescents psychology. These psychological disturbances could involve disturbed body image, social isolation, anxious and depressive manifestations, impaired quality of life, and low self- esteem $(3,5)$. As far as self-esteem, in particular, is concerned, it seems controversial whether there is a relationship between short stature in children with GHD and low self-esteem or not. This divergence may be due to that selfesteem has commonly been assessed by the children's parents while a few studies have been conducted based on questionnaires signed by the children themselves (6). It is noteworthy to mention that self-esteem has two contingencies: an intrinsic contingency where self-esteem is affected by whether one's actions are self-congruent and conducive to a personal growth, and an extrinsic contingency corresponding to social, school, and familial factors (7).

\section{Objectives}

The present study evaluates the self-esteem in children and adolescents with GHD via a self-report questionnaire, not exclusively based on parental perceptions. Moreover, since surveys carried out in Tunisia have primarily focused on the organic side of GHD, and as the self-esteem has yet to be explored, our study aimed to emphasize the relationship between GHD and low self-esteem, and to reveal influencing factors that should be dealt with in order to relieve 
those children from this psychological burden.

\section{Methods}

A cross-sectional comparative study was conducted on two groups of children and adolescents during a period of one year (January to December 2012).

\subsection{Subjects}

The first group included 30 children and adolescents, aged between 8 and 18 years, affected by a total deficit in GH. All these patients were being treated by the synthetic GH ( 6 days a week in 23 cases and 7 days a week in 7 cases) and followed in the pediatric department of the Hedi Chaker University Hospital of Sfax. The second group included 60 children and adolescents examined in a community clinic in Sfax for benign acute medical condition (flu and so on). Children and adolescents of the two groups were matched for age, sex, and socioeconomic status. The mean age of each group was 13 years $( \pm 3.16)$. The ethnic composition was the same in both groups (100\% Caucasian). In the present study, we included all children and adolescents aged between 8 and 18 years, being followed for a total deficit of GH confirmed by two GH simulation tests (Insulin and Propranolol glucagon stimulation tests). The diagnosis of GHD was based on GH value of less than $5 \mathrm{ng} / \mathrm{mL}$. On the other hand, patients presenting a staturoponderal delay, secondary to another pathology (celiac disease, Turner syndrome, chronic visceral disease, Crohn disease, renal insufficiency, tubulopathy, and metabolic disease), patients aged under 8 or more than 18 , and patients presenting a GHD untreated by the biosynthetic GH were excluded.

\subsection{Assessments}

For each patient included and his parent (father or mother), a clinical interview based on a predetermined format was done by a child and adolescent psychiatrist. The interviews were held in an atmosphere of confidentiality in an examination room in the pediatric department of the Hedi Chaker University Hospital of Sfax.

\subsection{Instruments}

These interviews followed a predetermined format to disclose the socio-demographic information (age, school performance, and parents' level of education) and semiological data (size at diagnosis, age at beginning of treatment, family relationship, peers-child relationship, cognitive disturbances such as sluggishness, attention deficit disorder, and memory disturbances, GHD whether associated with thyroid-stimulating hormone deficiency (TSHD) or not, growth retardation recognition whether by parents or physicians, and parents acceptance of the illness). The written parental consent to participate in this study was requested.

Self-esteem was measured by Coopersmith SelfEsteem-Inventory(SEI). The Coopersmith SEI is a self-report instrument of 58 items to which each subject responds "like me" or "unlike me." The present study used the Arabic translation of the Coopersmith SEI, in its school form for the ages 8-15. The Coopersmith SEI was developed through research to assess attitude toward oneself in general and in specific contexts. It consists of four subscales designed to assess the perception of self (General self-subscale: 26 items), peers (Social self-peer subscale: 8 items), parents (Home-parents subscale: 8 items), and school (Schoolacademic subscale: 8 items). The total self-score was computed by summing up the four subscale scores. The sum of the four subscales represented the total SEI score ranging between 0 and 100. Children or adolescents have a positive self-image if scores are in general subscale $>$ 18.64 , social subscale $>5.67$, familial subscale $>4.92$, school subscale $>4.12$, and total subscale $>33.35$. The subscales were grouped into two contingencies: intrinsic contingency represented by the general subscale, and extrinsic contingency encompassing social, familial, and school-academic subscales.

\subsection{Statistics}

Statistical analysis was performed by using the SPSS statistical package, version 11.0. The Chi-square test was used to compare the frequencies and the $t$-test to compare the means. Rejection of the Null hypothesis was set at $\mathrm{P}<0.05$.

\section{Results}

\subsection{Sample Identification}

The mean age of our patients at the time of diagnosis was six (ranging from 3 to 14 years) while the mean age of our patients at the time of the study was 13 (ranging from 8 to 18 years). $46 \%$ of the patients were aged 12 years or less and the remaining patients (54\%) were aged over 12 . The sample was male-dominated with a sex ratio of $2.3 .23 \%$ of the cases were from rural areas while $77 \%$ were from urban areas. In the present study, the inbreeding rate was $36.7 \%$. A parental small size was found to be $6.7 \%$ among fathers and $13.3 \%$ among mothers. The majority of our patients representing $90 \%$ attended school: $60 \%$ were at the basic school level while $30 \%$ were at the secondary school level. Two of our patients $(6.7 \%)$ received vocational training. Only one patient (3.3\%) had never attended school. The grade repetition rate was $33.3 \%$ although $80 \%$ had a mid to good school 


\begin{tabular}{|c|c|c|c|}
\hline & GHD Group & Control Group & P Value \\
\hline \multicolumn{4}{|l|}{ Home-parents subscale } \\
\hline Mean \pm SD & $5.1 \pm 1.44$ & $5.7 \pm 1.67$ & 0.81 \\
\hline Low self-esteem,\% & 40 & 18 & 0.026 \\
\hline \multicolumn{4}{|l|}{ School-academic subscale } \\
\hline Mean $\pm S D$ & $4.77 \pm 1.56$ & $5.43 \pm 1.63$ & 0.067 \\
\hline Low self-esteem,\% & 54 & 26 & 0.01 \\
\hline \multicolumn{4}{|l|}{ Social self-peer subscale } \\
\hline Mean $\pm S D$ & $5.1 \pm 1.56$ & $5.2 \pm 1.3$ & 0.75 \\
\hline Low self-esteem, \% & 60 & 56 & 0.76 \\
\hline \multicolumn{4}{|l|}{ General subscale } \\
\hline Mean $\pm S D$ & $14 \pm 4.7$ & $18.1 \pm 5.2$ & 0.001 \\
\hline Low self-esteem, \% & 84 & 33 & 0.000 \\
\hline \multicolumn{4}{|l|}{ Total subscale } \\
\hline Mean \pm SD & $29 \pm 7.1$ & $34.6 \pm 7.5$ & 0.001 \\
\hline Low self-esteem, \% & 80 & 33 & 0.000 \\
\hline
\end{tabular}

Abbreviations: GHD, growth hormone deficiency; SEI, self-esteem inventory.

performances. The results of the different hormonal explorations revealed an isolated GHD rate of $76.6 \%$ and an associated GHD with TSHD rate of $23.4 \%$. All the patients were small sized.

\subsection{Self-Esteem}

Table 1 compares the means and pathological rates in SEI in the two studied groups across the studied subscales. Tables 2, 3, 4, 5, and 6 show the correlations between individual and illness-related factors and self-esteem respectively in total, general, school, social, and familial subscale.

\section{Discussion}

In this study, patients with GHD had low self-esteem on the five subscales: familial, school, social, general, and total. The differences were significant in all subscales except the social subscale.

Several studies revealed a self-esteem decline in patients with GHD $(8,9)$. In fact, the physical performances decline in these patients may result in the decline in selfesteem $(10,11)$. Some studies demonstrated that patients with GHD had a comparable self-esteem decline with those having chronic disease such as diabetes or asthma $(12,13)$. Nevertheless, the link between GHD and self-esteem decline is not unanimously accepted $(14,15)$. For some authors, it is rather the child personal perception of his size that influences self-esteem than the real size $(8,15)$.
Table 2. Self-Esteem Correlated Factors in Children and Adolescents with GHD in the Total Subscale

\begin{tabular}{lccc}
\hline Self-Esteem in the Total Subscale & High, \% & Low, $\%$ & P Value \\
\hline School performance & 0 & 21.73 & 0.01 \\
\hline Low & 100 & 78.26 & \\
\hline Mid to high & & & 0.005 \\
\hline GHD $\quad$ & 87.5 & 33.33 & \\
$\quad$ Isolated & 12.5 & 66.66 & \\
\hline Associated with TSHD & & & 0.01 \\
\hline $\begin{array}{l}\text { Parents acceptance of the illness } \\
\text { Yes }\end{array}$ & 83.33 & 100 & \\
\hline No & 16.66 & 0 & \\
\hline $\begin{array}{l}\text { Disturbance in parent-child } \\
\text { relationship perceived by parents }\end{array}$ & & & 0.02 \\
\hline No & 66.66 & 5.88 & \\
\hline Yes & 33.33 & 94.11 & \\
\hline
\end{tabular}

Abbreviations: GHD, growth hormone deficiency; TSHD, thyroid-stimulating hormone deficiency.

Table 3. Self-Esteem Correlated Factors in Children and Adolescents with GHD in the General Subscale

\begin{tabular}{|c|c|c|c|}
\hline Self-Esteem in the General Subscale & High, \% & Low, \% & P Value \\
\hline Age & & & 0.02 \\
\hline$\leq 12$ & 72.72 & 31.57 & \\
\hline$>12$ & 27.27 & 68.42 & \\
\hline School performance & & & 0.01 \\
\hline low & 14.28 & 21.73 & \\
\hline Mid to high & 85.71 & 78.26 & \\
\hline GHD & & & 0.03 \\
\hline Isolated & 87.5 & 33.33 & \\
\hline Associated with TSHD & 12.5 & 66.66 & \\
\hline Parents acceptance of the illness & & & 0.02 \\
\hline Yes & 83.33 & 29.16 & \\
\hline No & 16.66 & 70.83 & \\
\hline $\begin{array}{l}\text { Disturbance in parent-child } \\
\text { relationship perceived by parents }\end{array}$ & & & 0.02 \\
\hline No & 50 & 29.16 & \\
\hline Yes & 50 & 70.83 & \\
\hline $\begin{array}{l}\text { Disturbance in parent-child } \\
\text { relationship perceived by child }\end{array}$ & & & 0.02 \\
\hline No & 40 & 44 & \\
\hline Yes & 60 & 56 & \\
\hline
\end{tabular}

Abbreviations: GHD, growth hormone deficiency; TSHD, thyroid-stimulating hormone deficiency. 
Table 4. Self-Esteem Correlated Factors in Children and Adolescents with GHD in the School-Academic Subscale

\begin{tabular}{|c|c|c|c|}
\hline Self-esteem in the school subscale & High, \% & Low, \% & P Value \\
\hline School performance & & & 0.03 \\
\hline Low & 7.14 & 26.66 & \\
\hline Mid to high & 92.85 & 73.33 & \\
\hline Growth retardation recognition & & & 0.01 \\
\hline Parents & 7.14 & 37.5 & \\
\hline Physicians & 92.85 & 62.5 & \\
\hline
\end{tabular}

Abbreviation: GHD, growth hormone deficiency.

Table 5. Self-Esteem Correlated Factors in Children and Adolescents with GHD in the Social Self-Peer Subscale

\begin{tabular}{|c|c|c|c|}
\hline Self-esteem in the social subscale & High, \% & Low, \% & PValue \\
\hline Sex & & & 0.03 \\
\hline Male & 90.90 & 57.89 & \\
\hline Female & 9.09 & 42.10 & \\
\hline School performance & & & 0.05 \\
\hline Low & 15.38 & 23.52 & \\
\hline Mid to high & 84.61 & 76.47 & \\
\hline Cognitive disorders & & & 0.03 \\
\hline Yes & 33.33 & 61.11 & \\
\hline No & 66.66 & 38.88 & \\
\hline Father's level of education & & & 0.05 \\
\hline Illiterate/primary & 41.66 & 77.77 & \\
\hline$\geq$ Secondary & 58.33 & 22.22 & \\
\hline GHD & & & 0.05 \\
\hline Isolated & 83.33 & 72.22 & \\
\hline Associated with TSHD & 16.66 & 27.77 & \\
\hline $\begin{array}{l}\text { Disturbance in parent-child } \\
\text { relationship perceived by parents }\end{array}$ & & & 0.03 \\
\hline No & 66.66 & 27.77 & \\
\hline Yes & 33.33 & 72.22 & \\
\hline
\end{tabular}

Abbreviations: GHD, growth hormone deficiency; TSHD, thyroid-stimulating hormone deficiency.

\subsection{Factors Influencing Self-Esteem}

GHD associated with TSHD type was significantly correlated with low self-esteem, particularly in the total $(\mathrm{P}=$ $0.05)$, general $(P=0.03)$, and social $(P=0.05)$ subscales. This is in line with the results of several studies $(1,16,17)$. In fact, the association of two pathologies and its repercussions, as well as treatment multiplication, could negatively affect self-esteem.

In this study, relationship disturbances between child and father were correlated with low self-esteem in total,

\begin{tabular}{|c|c|c|c|}
\hline & High, \% & Low, \% & P Value \\
\hline Age at the beginning of treatment & & & 0.02 \\
\hline$<8$ & 66.66 & 25 & \\
\hline$\geq 8$ & 33.33 & 75 & \\
\hline Size at diagnosis & & & 0.05 \\
\hline$-2 \mathrm{SD},-3 \mathrm{SD}$ & 11.11 & 41.66 & \\
\hline$<-3 \mathrm{SD}$ & 88.88 & 58.33 & \\
\hline $\begin{array}{l}\text { Disturbance in peers-child relationship } \\
\text { perceived by peers }\end{array}$ & & & 0.01 \\
\hline No & 61.11 & 8.33 & \\
\hline Yes & 38.88 & 91.66 & \\
\hline $\begin{array}{l}\text { Disturbance in parent-child } \\
\text { relationship perceived by parents }\end{array}$ & & & 0.01 \\
\hline No & 64.70 & 7.69 & \\
\hline Yes & 35.29 & 92.30 & \\
\hline
\end{tabular}

Abbreviation: GHD, growth hormone deficiency.

general, social, and familial subscales. A harmonious relationship between the child and his father is associated with better psychological adjustment for children. The father could influence indirectly his child physical health and well-being: global social competence, the spirit of initiative on the social level, social maturity, and capacity to establish contacts with others $(3,18)$. Moreover, the father is involved in building the child personality, by fostering autonomy and self-sufficiency necessary to maintain a balanced affective life, and by enhancing self-confidence useful for the upcoming competences, which may be hampered by the illness $(2,3)$.

In the present study, peers relationship disturbances were correlated with low self-esteem in the familial subscale $(P=0.01)$. This is in line with Pendley et al. (19) and Seiffge-Krenke (20) studies.

Pendley et al. (19) demonstrated that daily treatment is the main source of patients' concerns, particularly in adolescence. Indeed, adolescent feels deprived of his liberty. Thus, this freedom infringement caused by the disease and this feeling of being different from others are the factors that influence self-esteem. Seiffge-Krenke (20) noticed that because of their chronic disease, many patients feel compelled to live a restrictive social life. Youths who are entering their teens seek to care for themselves, thus acquiring their autonomy. At this age, making comparisons between peers have a crucial role, and sick adolescents experience feelings of worthlessness and rejection. All these feelings have a negative impact on self-esteem (1).

In the present study, self-esteem in the general subscale 
was significantly more negative in adolescence (age $>12$ years old $)(P=0.02)$. In the same way, Atkin and Ahmad (21) noted that some adolescents, generally at 12 , ask the question "why me?" when they compare their lives with their friends' lives, as the disease imposes serious life restrictions. These adolescents deal with the risk to become withdrawn, to develop complex, to experience social relationship disruptions and consequently, to an unbalance and negative self-image. Besides, adolescents, in general, tend to seek independence and autonomy, which could be hindered by their illness.

In the present study, the late age at the beginning of treatment was significantly correlated with low selfesteem in the familial subscale $(\mathrm{P}=0.02)$. In this sense, Ross et al. (16) demonstrated the impact of late-onset treatment on self-esteem. Marcelli (22) evidenced that body map damage, or rather the "sense of self" damage in its broadest sense, depends on seriousness, duration, and nature of the disease. Concerning treatment, Alvin et al. (1) noticed that self-image is influenced by the number of medications and by the number of daily medical intake. The increased number of daily injections could help relieve psychological stress and foster compliance.

As outlined in the present study, there was a significant correlation between female sex and low self-esteem in the social subscale $(P=0.03)$. In fact, in our culture, being a woman is generally associated with the female stereotyped social roles as spouse and mother. Regrettably, a healthy girl will be more likely to get married and to have children than a sick girl. Thereby, they would probably be more fulfilled socially. According to the study of Chaplin carried out on prepubertal children with GHD, girls have a lower selfesteem than boys do.

A significant correlation was demonstrated between growth retardation between -2 DS and -3 DS and low selfesteem $(P=0.05)$. This parallels the data of the literature demonstrating that short children have an impaired selfconcept as expressed by feelings of unpopularity and dissatisfaction and that they tend to view themselves less favorably than do their taller peers (23).

\subsection{Conclusion}

Overall, the results of our investigation contributed to the current debate over the relationship between GHD in children and adolescents and self-esteem and provided evidence for low self-esteem in GH impaired children and adolescents alongside several other studies. It also revealed several factors influencing the self-representation of these patients. This highlights the importance of early screening and psychological care to avoid the emergence of a characterized mental disease.
Thus, the findings presented here do not extend to the psychological benefits of GH treatment. In order to further elucidate this fact, there is a clear need for a controlled study of the GH treatment effect over a Tunisian sample.

\section{Footnotes}

Authors' Contribution: Study concept and design: Héla Ayadi, Leila Cherif, Imen Hadjkacem, Wiem Kammoun, Khaoula Khemakhem and Souhel Khemekhem; acquisition of data: Héla Ayadi and Souhel Khemekhem; analysis and interpretation of data: Héla Ayadi, Leila Cherif, Wiem Kammoun and Souhel Khemekhem; drafting of the manuscript: Héla Ayadi, Leila Cherif, Imen Hadjkacem, Wiem Kammoun, Yousr Moalla and Farhat Ghribi; critical revision of the manuscript for important intellectual content: Héla Ayadi, Leila Cherif, Khaoula Khemakhem, Yousr Moalla, Thouraya Kammoun, Mongia Hachicha and Farhat Ghribi; statistical analysis: Héla Ayadi, Leila Cherif and Souhel Khemekhem; administrative, technical, and material support: Yousr Moalla, Thouraya Kammoun, Mongia Hachicha and Farhat Ghribi; study supervision: Héla Ayadi, Leila Cherif, Yousr Moalla, Thouraya Kammoun, Mongia Hachicha and Farhat Ghribi.

Conflict of Interests: The authors report no actual or potential conflict of interests.

\section{References}

1. Alvin P, Rey C, Frappier JY. [Therapeutic compliance in adolescents with chronic disease]. Arch Pediatr. 1995;2(9):874-82. French. doi: 10.1016/0929-693X(96)81267-X. [PubMed: 7581786].

2. Fedala NS, Haddam AEM, Meskine D, Chentli F. Répercussion du déficit en GH sur le développement neuropsychique : à propos d'une série de 120patients. Ann Endocrinol (Paris). 2015;76(4):384-5. French. doi: 10.1016/j.ando.2015.07.262.

3. Marcelli D. L'enfant dans sa famille. In: Cohen D, editor. Enfance et psychopathologie. France: Elsevier Health Sciences France; 1995. p. 465-88. French.

4. Klose M. Quality of life in adult hypopituitary patients treated for growth hormone deficiency. Open Endocrinol J. 2012;6(1):91-102. doi: 10.2174/1874216501206010091.

5. Kamoun T, Kmiha S, Khemakhem S, Kamoun F, Telmoudi J, Chabchoub I, et al. SFP PC-04 - Profil psychologique des enfants atteints de déficit en hormone de croissance : étude de 30 observations. Arch Pediatr. 2014;21(5):894. French. doi:10.1016/s0929-693x(14)72154-2.

6. Erling A, Wiklund I, Albertsson-Wikland K. Prepubertal children with short stature have a different perception of their well-being and stature than their parents. Qual Life Res. 1994;3(6):425-9. doi: 10.1007/BF00435394. [PubMed: 7866360].

7. Ninot G, Delignieres D, Fortes M. L'évaluation de l'estime de soi dans le domaine corporel. Revue S.T.A.P.S. 2000;53:35-48. French.

8. Chaplin JE, Kristrom B, Jonsson B, Hagglof B, Tuvemo T, Aronson AS, et al. Improvements in behaviour and self-esteem following growth hormone treatment in short prepubertal children. Horm Res Paediatr. 2011;75(4):291-303. doi: 10.1159/000322937. [PubMed: 21304250]. 
9. Hull KL, Harvey S. Growth hormone therapy and quality of life: Possibilities, pitfalls and mechanisms. J Endocrinol. 2003;179(3):311-33. doi: 10.1677/joe.0.1790311. [PubMed: 14656202].

10. Blum WF, Shavrikova EP, Edwards DJ, Rosilio M, Hartman ML, Marin F, et al. Decreased quality of life in adult patients with growth hormone deficiency compared with general populations using the new, validated, self-weighted questionnaire, questions on life satisfaction hypopituitarism module. J Clin Endocrinol Metab. 2003;88(9):4158-67. doi: 10.1210/jc.2002-021792. [PubMed: 12970281].

11. Juul A, Behrenscheer A, Tims T, Nielsen B, Halkjaer-Kristensen J, Skakkebaek NE. Impaired thermoregulation in adults with growth hormone deficiency during heat exposure and exercise. Clin Endocrinol (Oxf).1993;38(3):237-44. doi: 10.1111/j.1365-2265.1993.tb01001.x. [PubMed: 8458095].

12. Norrby U, Nordholm L, Andersson-Gare B, Fasth A. Health-related quality of life in children diagnosed with asthma, diabetes, juvenile chronic arthritis or short stature. Acta Paediatr. 2006;95(4):450-6. doi: 10.1080/08035250500437499. [PubMed:16720493].

13. Wallymahmed ME, Foy P, MacFarlane IA. The quality of life of adults with growth hormone deficiency: Comparison with diabetic patients and control subjects. Clin Endocrinol (Oxf).1999;51(3):333-8. doi: 10.1046/j.1365-2265.1999.00802.x. [PubMed: 10469013].

14. Zimet GD, Cutler M, Litvene M, Dahms W, Owens R, Cuttler L. Psychological adjustment of children evaluated for short stature: A preliminary report. J Dev Behav Pediatr. 1995;16(4):264-70. doi: 10.1097/00004703-199508000-00009. [PubMed: 7593662].

15. Cramer JA, Claude Simeoni M, Auquier P, Robitail S, Brasseur P, Beresniak A. Brief report: A quality of life instrument for adolescents with growth disorders. J Adolesc. 2005;28(4):595-600. doi: 10.1016/j.adolescence.2004.11.003. [PubMed:16022892].

16. Ross JL, Sandberg DE, Rose SR, Leschek EW, Baron J, Chipman JJ, et al. Psychological adaptation in children with idiopathic short stature treated with growth hormone or placebo. J Clin Endocrinol Metab. 2004;89(10):4873-8. doi: 10.1210/jc.2004-0791. [PubMed: 15472178].

17. Murata T, Shimizu A, Mori Y, Ohshima S. Depression in elementary school children. An evaluation using birleson's depression self-rating scale for children. Saishin Seishin Igaku.1996;1:131-7.

18. Epelbaum C, Ferrari P. Réactions psychologiques à la maladie chez l'enfant. Psychiatrie de l'enfant et de l'adolescent, chap. 54. Paris: Flammarion, coll. « Médecine sciences »;1995. p. 452-6.

19. Pendley JS, Kasmen LJ, Miller DL, Donze J, Swenson C, Reeves G. Peer and family support in children and adolescents with type 1 diabetes.JPediatr Psychol.2002;27(5):429-38. doi:10.1093/jpepsy/27.5.429. [PubMed: 12058007].

20. Seiffge-Krenke I. Chronic disease and perceived developmental progression in adolescence. Dev Psychol. 1998;34(5):1073-84. doi: 10.1037/0012-1649.34.5.1073. [PubMed: 9779752].

21. Atkin K, Ahmad WIU. Living a 'normal' life: Young people coping with thalassaemia major or sickle cell disorder. Soc Sci Med.2001;53(5):61526. doi: 10.1016/s0277-9536(00)00364-6.

22. Marcelli D. Psychopathologie des fonctions cognitives. In: Cohen D, editor. Enfance et psychopathologie. France: Elsevier Health Sciences France; 2006. p. 165-90. French.

23. Gordon M, Crouthamel C, Post EM, Richman RA. Psychosocial aspects of constitutional short stature: Social competence, behavior problems, self-esteem, and family functioning. J Pediatr. 1982;101(3):47780. doi: 10.1016/S0022-3476(82)80093-0. [PubMed: 7108676]. 